\title{
PENINGKATAN KOSUMSI SAYUR PADA ANAK MELALUI KEGIATAN MENANAM SAYUR
}

\author{
Ayu Mustika Sari ${ }^{1}$, M. Anggarayni² \\ Fakultas Keguruan dan Ilmu Pendidikan, Universitas Dharmas Indonesia \\ Email : ayumustikasari10@gmail.com ${ }^{1}$, melisaanggrayni81@gmail.com²
}

\begin{abstract}
Abstrak
Pertumbuhan anak usia dini yang optimal tergantung pelaksanaan perilaku sehat. Kesehatan dan gizi bisa dibentuk melalui pembiasaan makan sayur sejak dini. Namun kenyataannya konsumsi buah dan sayur pada anak sangat rendah sekali. Dari hasil pengamatan dan wawancara yang di lakukan kepada orang tua wali murid di TK Islam Terpadu Yadiaksa dari 15 orang anak yan diwawancarai hanya 4 orang anak yang menyukai sayur. Fakta kurang konsumsi sayur dan buah yang merata pada anak-anak menunjuk kepada kebiasaan kurang konsumsi sayur yang dimulai sejak dini. Berdasarkan permasalahan, peneliti memberikan solusi mengatasi dengan melaksanakan pelatihan terkait peningkatan manfaat sumberdaya orangtua wali murid dan lahan pekarangan dengan menanam sayuran yang sehat membantu pertumbuhan Anak Usia Dini. Kegiatan ini berkontribusi secara mendasar untuk peningkatan kosumsi sayur pada anak dengan persentase peningkatan menjadi $80 \%$ anak menyukai sayur dan jika sayur diolah menjadi cemilah $100 \%$ anak menyukai sayur.
\end{abstract}

Kata kunci: Kosumsi Sayur, Menanam sayur

\begin{abstract}
An optimal early childhood growth depends on how healthy behavior is being implemented. Health and nutrition can be formed through the habit of eating vegetables from an early age. However, the amount of consumption of fruits and vegetables in children is very low. It is proved by observations and interviews of 15 students' parents in TK Islam Terpadu Yadiaksa. There were only 4 children who liked vegetables. The fact showed that the uneven amount of the consumption of vegetables and fruits might be referred to the lack of habit in consuming vegetables at an early age. Thus, the researcher provides a solution to overcome this condition by conducting training to utilize the parents and their back or front yard by planting healthy vegetables as resources to help the Early Childhood growth. The findings showed that the activity contributes increasing the percentage of the consumption of vegetables to children up to $80 \%$. Also, $100 \%$ of children like vegetables if they are processed into snacks.
\end{abstract}

Keywords: vegetable consumption, planting, liking vegetables 


\section{PENDAHULUAN}

Enam tahun pertama seorang anak merupakan hal yang sangat penting karena terjadi pembentukan jaringan dan perkembangan yang sangat cepat. Salah satu di antaranya adalah dalam proses pembentukan otak dan berdampak terhadap tingkat kecerdasan. Otak manusia adalah salah satu modal pertumbuhan yang sangat pesat.

Tumbuh berkembangnya anak usia dini yang optimal tergantung pelaksanaan Perilaku Sehat. Kesehatan dan gizi bisa dibentuk melalui pembiasaan makan buah dan sayur pada Anak Usia Dini. Namun pada kenyataannya konsumsi Buah dan Sayur pada anak sangat rendah sekali.

Dari hasil pengamatan dan wawancara yang pengelola lakukan kepada orang tuadi PAUD Islam Terpadu Yadiaksa rata-rata anak yang berada di TK atau PAUD dari 15 orang anak hanya 4 orang atau $30 \%$ anak yang suka makan sayur dan buah dan $70 \%$ anak tidak suka mengkonsumsi buah dan sayur. $30 \%$ anak yang suka makan buah dan sayur hanya buahbuah pilihan dan sayur-sayur pilihan. Padahal, memperkenalkan sayur dan buah secara bertahap dan teratur pada anak akan membentuk preferensi terhadap sayur dan buah yang akan mereka bawa sampai usia dewasa.

Bahkan ironisnya, dari hasil Riset Dasar Kesehatan (Riskesdas) 2013 menyebutkan, rerata nasional perilaku konsumsi kurang sayur dan atau buah penduduk usia 10 tahun ke atas sebesar 93,5\%. Artinya, hanya 6,5\% masyarakat Indonesia yang sudah cukup mengonsumsi sayur dan buah. Fakta kurang konsumsi sayur dan buah yang merata pada anak-anak maupun orang dewasa di Indonesia menunjuk kepada kebiasaan kurang konsumsi sayur dan buah yang dimulai sejak dini.

Berdasarkan permasalahan tersebut diatas maka peneliti berinisiatif untuk mengalangkan gerakan pentingnya sayur dan bauh bagi anak, mengajak pengasuh, orangtua dan anak menanam sayur, merawat sayur, memetik dan membiasakan anak mengkonsumsi sayur. Dengan namagerakan "Ayo Menanam, konsumsi sayur dan sukai sayur".

Kegiatan menanam sayur dapat membantu membakar energi yang cenderung berlebihan pada anak dan orang tua, mengendalikan suasana hati dengan keindahan, mengembangkan sistem kekebalan tubuh yang kuat, memberikan rasa tanggung jawab untuk menjaganya, dan mendorong anak mengonsumsi lebih banyak sayuran. Selain itu manfaat berkebun yang pengelola dirasakan yaitu dapatnya memanfaatkan lingkungan dengan maksimal, memanfaatkan bahan-bahan bekas dan pengolahan sampah organik dengan maksimal, selain itu dapat memberi tahu orang tua pentingnya mengkonsumsi sayur pada anak Usia Dini. Peneliti mengajak orang tua dan pengasuh melakukan gerakan "Ayo Menanam, konsumsi sayur dan sukai sayur”. Orang tua, 
penglola, pendidik dan Anak diminta untuk menanam sayur, merawat sayur, memetik sayur, memasak sayur, membuat cemilan dari sayur, Membiasakan terus kepada anak memakan sayur sehingga terbentuk pola pikir bahwa sayur adalah kebutuhan.

Diharapkan program "Ayo menanam, konsumsi sayur dan sukai sayur" dapat menigkatkan kesadaran masyarakat lingkungan sekitar sekolah untuk dapat memanfaatkan lingkungan semaksimal mungkin, mengolah sampah organik menjadi pupuk, memanfaatkan botol-botol bekas, kaleng bekas untuk wadah menam sayur, serta memberi tahu kepada orang tua pentingnya sayur dan buah bagi Anak Usia Dini dan membiasakan anak untuk mengkonsumsi buah dan sayur.

\section{METODE PENELITIAN}

\section{Jenis Penelitian}

Metode Peneitian digunakan dalam ini adalah peneliti tindakan kelas. Implikasi dalam penelitian ini dilakukan secara kolaborasi artinya penelitian dapat berkolaborasi atau bekrjasama dengan guru dan orang tua di TK Islam Terpadu Yadiaksa sebagai mitra dalam penelitian yang bertujan untuk membantu meningkatkan kosumsi sayur pada anak. Maka penelitian tindakan kelas ini bersifat partisifasif dan kolaboratif.

\section{Waktu Penelitian}

Penelitian dikasanakan pada semester 1 Juli - November 2019. Pelaksanaan siklus I pada Tanggal 16 juli, dan siklus II pada tangga 3 september.

\section{Subjek Penelitian}

Subjek peneitian tindakan kelas adalah anak didik TK Islam Terpadu Yadiaksa Sungai Rumbai Kab.Dharmasraya tahun pelajaran 2019/2020 denga jumlah siswa 15 orang anak.

Sumber data dibedakan atas promer dan sekunder. Sumber daa primer adalah objek yang diobservasi langsung di lapangan dan para informan dan pemberi informasi yang diwawancarai. Pada penelitian ini yang bertindak sebagai data primer adalah anak guru dan orang tua.

Sumber data sekunder berupa dokumnetasi dan arsip-arsip resmi yang dapat mendukung hasil penelitian. Data sekunder ini sangat berharga bagi peneliti guna memahai lebih mendalam tetang masalah yang sedang diteliti.

\section{Tempat Penelitian}

Penelitian ini merupakan penelitian tindakan kelas yang dilakukan di TK Islam Terpadu Yadiaksa Sungai Rumbai Kab.Dharmasraya.

\section{Desain Penelitian}

Pendekatan yang digunakan dalam penelitian ini adalah penelitia kualitatif untuk mengetahui kondisi dan temuan-temuan yang ada di lapangan yaitu dengan desains 2 siklus. Penelitian tindakan kelas akan dilaksakan dengan mengikuti tahapan Kurt Lewin. Hubungan antar tahapan yang dikemukan Kurt Lewi sebagai berikut. 


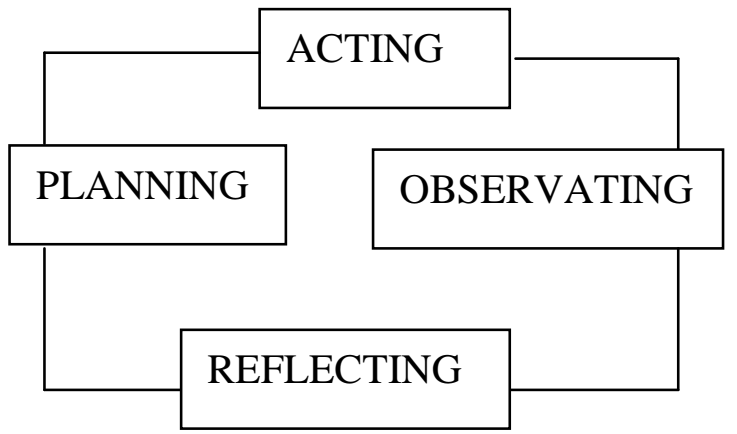

Gambar 1. Desain Model Kurl Lewin

Tahapan-tahapan diatas yang membentuk siklus dapat dilanjutkan ke siklus berikutnya dengan rencana, tindakan, pengamatan, dan refleksi ulang berdasarkan hasil yang yang dicapai pada siklus sebelumnya.

\section{Analisis Data}

Miles dan Huber (Agusta, 2003;10) mendenfinisikan penyajian data adalah kegiatan ketika sekumpulan informasi disusun, sehingga memberikan kesimpulan dan pengambilan tindakan. Bentuk penyajian data kualitatif berupa teks narasif: berbentuk catatan lapangan; matriks, grafik, jaringan dan bagan. Berdasarkan pemaparan teknik analisi data Mils dan Huberman, maka peneliti dalam menganalisis data menggunakan teknik data analisis interaktif.

\section{HASIL PENELITIAN DAN PEMBAHASAN}

Berkebun adalah sarana yang sangat baik untuk mengasah kepekaan dan kecintaan anak terhadap lingkungan hidup, karena ia akan mengamati secara langsung cara kerja alam. Kegiatan tersebut berfungsi melatih gerakan- gerakan tangan, jari jemari anak akan berkembang secara optimal. Saat berkebun anak-anak akan memiliki banyak ruang untuk bergerak dan melatih tubuh dengan gerakangerakan skala besar seperti menggali, menggaruk, berlari dan membungkuk.

Dalam melakukan aktivitas berkebun, anak menggunakan beragam media, mulai dari hidrogel, tanah, pupuk, sekop, dll. Berkebun memberikan pengalaman tersendiri bagi anak. Anak melakukan pencampuran sendiri tanah dan pupuk,, menyemai bibit, menyirami dan memindahkan media semai kewadah barang bekas seperti botol minuman, kaleng bekas dan melakukan penjagaan dan penyiraman samapai mereka memetik hasil tanamannya.

Program yang dilakukan pengelola "Ayo menanam, konsumsi sayur dan sukai sayur" dimulai dari permintaan bibit sayuran yang diminta kedinas pertania Kec.Koto Salak, setelah bibit didapatkan pengelola barulah membawa orang tua anak dan pengasuh membibit didalam wadah yang sudah disiapkan.Menyiapkan Wadah atau media tanam untuk penyemaian, satu minggu setelah disemai bibit bisa dibindah kemedia tanam. Melakukan penanaman sayuran yang ditanam tampa petisida dan hanya menggunakan pupuk organik dari kotoran sapi dan pembakaran sampah sehingga sayur yang di hasilkan bagus dan sehat. Proses penanaman dilakukan oleh pengelola, pengasuh, anak dan orang tua. 
Pengelola menggalangkan guru pengasuh, orang tua bergontoroyong bersama mengajarkan anak - anak cara membibit, dan memindahkan hasil semai kemedia bekas sampai pada perawatan pada tanaman sayuran. Kegiatan gotoroyong dilakukan sekali dalam seminggu. Berikut foto kegiatan anak merawat sayur.

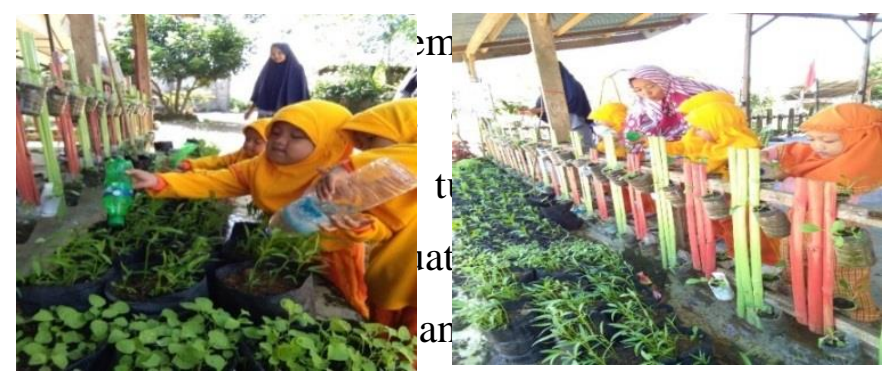

anak - anak menyukai sayuran melalui produk inovatif dari tanaman seperti stik, kripik, crispy, bulo dan cemilan lain.
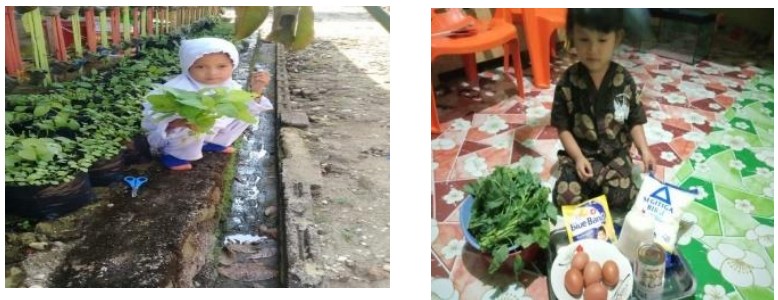

Gambar 3. kegiatan pengolahan sayur bayam menjadi roti.

Pada waktu siang hari pengasuh memasakkan sayur. Sekali dalam satu minggu sekali orang tua anak dimintak membuat cemilan dari sayur.

Pembiasaan mengkonsumsi sayuran juga dilakukan melalui kegiatan memasak bersama pengasuh dan orang tua, menyajikan sayuran setiap makan.

Strategi pengelolan program"Ayo menanam, konsumsi sayur dan sukai sayur", melalui 3 kegiatan yaitu program kegiatan berkebun, program kegiatan mengkonsumsi sayur, dan kegiatan menyukai sayur.

\section{Kegiatan Berkebun}

Kegiatan menanam dilakukan satu kali dalam satu minggu, yang melibatkan pengelola, orang tua, dan pengasuh. Kegiatan berkebun biasanya dilakukan pada hari sabtu mulai dari jam 08.00-12.00.

Dalam menanam sayur dilakaukan di TK Islam Terpadu YADIAKSA, dengan menggunakanpengolahan libah yaitu pupuk pupuk oraganik dan wadah yang digunakan untuk menanam sayuar yaitu dengan menggunakan palibek, kaleng bekas dan botol bekas minuman. Dalam proses perawatan sayur dilakukan oleh pengelola dan pengasuh TK serta mengajak anak dalam merawatnya. Anak diminta menyiram sayuran setiap hari, satu orang bertanggung jawab dengan 3 wadah penanaman.

Kegiatan mengkonsumsi sayur dilakukan dengan cara mengajak orang tua untuk membekali anak sarapan sayur, dikosumsi bersama seperti bakwan, bolu, kripik, stik dll.

\section{Kegiatan pembiasaan sehingga anak} menyukai sayur yaitu dengan mengubah pola cemilan anak menjadi cemilan sehat seperti stik bayam, kue kukus, bakwa sayur dll. Ketika anak memakan cemilan dari sayur yakinkan anak bahwa sayur bagus untuk kesehatan dan rasa sayur juga lezat dan nikmat sehingga membuat badan dan tubuh kita menjadi sehat. Jika setiap hari dingatkan dan dilakukan 
pembiasaan, secara otomatis anak merubah pola pikir anak bahwa sayur merupakan kebutuhan pokok bagi anak.

\section{Hasil yang Dicapai}

Hasil yang dicapai dari program pengelola "Ayo menanam, konsumsi sayur dan sukai sayur" adalah dapat memanfaatkan lahan secara maksimal mungkin dengan sesuatu yang bermanfaat. Pemanfaatan lagi bahan bekas, seperti botol bekas, kaleng bekas sebagai wadah penanam ,mendaur ulang sampah oraganik menjadi pupuk. Menubuhkan kebisaan anak dalam berkebun dengan berkebun banyak manfaat yang didapat diantaranya. Menumbuhkan minat makan sehat. Meningkatkan daya tahan tubuh Mengasah motorik anak (Meningkatkan koordinasi dan kekuatan tangan) Mengajarkan tanggung jawab pada anak, mempertajam memori dan focus, memberitakukan kepada orang tua pentingnya mengkonsumsi sayur bagi keluarga terutama bagi anak.embisakan anak untuk mengkonsumsi sayur. Membuat anak untuk menyukai sayur sebagai makan yang wajib dikonsumsi. Memudahkan orang tua untuk mendapatkan sayur yang sehat bebas dari peptisidan dan bahan-bahan kimia.

Hasil yang dicapai setelah terlaksananya program ini dapat dilihat dalam tabel berikut.

Grafikkonsumsi sayur anak TK Islam Terpadu Yadiaksa.

Dampak Implementasi Strategi Pengelolaan
Tabel Kondisi Awal

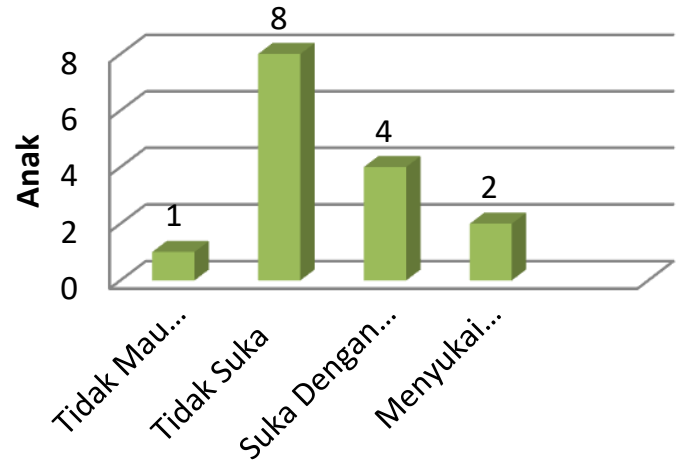

Gambar 4 kondisi awal konsumsi sayur

Setelah Tindakan

"Ayo Menanam Sayur, Kosumsi \& Sukai Sayur"

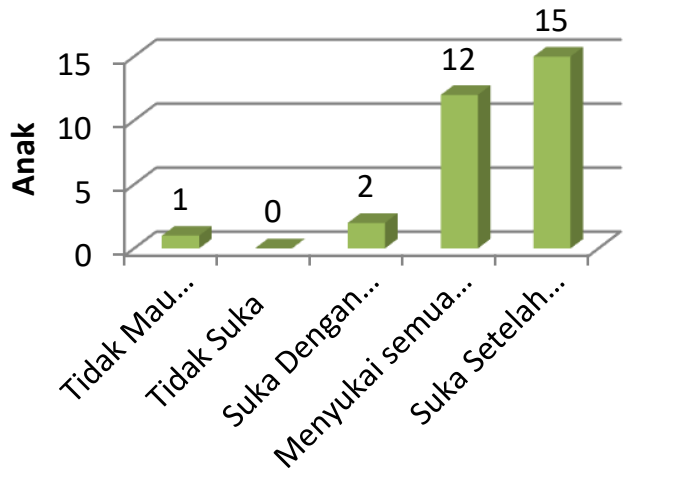

Gambar 5. kondisi setelah tindakan

Gerakan ini dapat menciptakan lingkungan TK yang asri, aman, nyaman, meningkatkan kerja sama antarapengelola, orang tua dan pemgasuh dalam pola asuh asah anak. Menyamakan persepsi orang tua dan pengasuh dalam membentuk karakter anak. Gerakan ini tidak hanya berdampak kepada lingkungan sekolah namun juga berdamapak pada masyarakat lingkungan sekitar tentang pentingnya memanfaatkan lingkungan sekitar 
dan pengolahan limbah rumah tangga secara bijak.

\section{SIMPULAN}

Program kegiatan pengelola "ayo menanam, kosumsi sayur dan sukai sayur" memberikan banyak manfaat bagi sekolah, pengasuh, orang tua, terutama anak tentunya, yaitu tentang bagaimana memanfaatkan sampah menjadi pupuk kompos, memanfaatkan pupuk organi, memanfaatkan botol dan kaleng bekas memaksimalkan ketermanfaatan lingkungan sekitar sekolah. Gerakan ini juga telah meningkatkan kosumsi sayur pada anak dan keluarga, dari data yang didapat setelah dilakuknnya gerakan ini mengkonsumsi sayur pada anak TK Islam Terpadu meningkat menjadi $80 \%$ anak menyukai sayur dan jika sayur diolah menjadi cemilah $100 \%$ anak menyukai sayur, sebelum adanya gerakan ini $75 \%$ anak yang tidak mengkonsumsi sayur. Jadi program ini dapat menigkatkan minat dan kesukaan anak untuk mengkonsumsi sayur.

Program pengelola "Ayo menanam, konsumsi sayur dan sukai sayur" dimulai dari permintaan bibit sayuran yang diminta kedinas pertania Kec.Koto Salak, setelah bibit didapatkan pengelola, pengasuh, orang tua dan anak menyemai didalam wadah yang sudah disiapkan. Menyiapkan Wadah atau media tanam untuk penyemaian, satu minggu setelah disemai bibit bisa dibindah kemedia tanam. Melakukan penanaman sayuran yang ditanam tampa petisida dan hanya menggunakan pupuk organik dari kotoran sapi dan pembakaran sampah sehingga tanaman yang di hasilkan bagus dan sehat. Proses penanaman dilakukan oleh pengelola, pengasuh, anak dan orang tua. Guru pengasuh, orang tua bergontoroyong bersama mengajarkan anak - anak cara membibit, dan memindahkan hasil semai kemedia bekas sampai pada perawatan pada tanaman sayuran. Kegiatan gotoroyong dilakukan sekali dalam seminggu. Dengan adanya kegiatan ini telah meningkat. Banyaknya jenis yang sudah tertanam dan biasa dipanen akan meningkatkan kosumsi sayur pada anak saat dijadikan makanan olahan yang berfariasi.

\section{DAFTAR PUSTAKA}

Agusta, I (2003) “ Teknik Pegumpulan dan Analisis Data Kualitatif" Makalah Pada pelatihan metode kualitatif dan pusat pelatihan Sosial Ekonomi. Libtang Pertanian, Bogor.

Murtie.S.C (2009). All About Kesehatan anak. Jkarta; Gramedia Pustaka Umum.

Santoso, S., Anne, L (2009). Kesehatan dan Gizi, Jakarta: Rineka Cipta.

Astutui, A, K. (2016). Perilaku Sehat Pada Anak Usia Dini di PAUD Purwomukti Desa Brikut Kecamatan Gatasan. Schoalaria Vol 6 (3) Hlm. 264-272.

Suwarsih Madya. (1999) Penelitian Tindakan Action Research Teori dan Praktek. Bandung: Alfabeta.

Sanusi, B. (2010). Sukses bertanam sayuran di lahan sempit. Jakarta: Agromedia Pustaka. 
https://media.neliti.com/media/publications/811

52-ID-perancangan-media-edukasimenanam-sayura.pdf.

Supriati, Y. \& Herliana, E. (2015). 15 sayuran organik dalam pot. Jakarta: Penebar Swaday 